Article

\title{
Development and Validation of Stability-Indicating Assay Method for a Novel Oxazolidinone (PH-192) with Anticonvulsant Activity by Using UHPLC-QToF-MS
}

\author{
Naser F. Al-Tannak ${ }^{1, *}$, Oludotun A. Phillips ${ }^{1}$, Husein J. Kamal ${ }^{1,2}$ and Ahmed Hemdan ${ }^{3}$ (D) \\ 1 Department of Pharmaceutical Chemistry, Faculty of Pharmacy, Kuwait University, P.O. Box 24923, \\ Safat 13110, Kuwait; oludotun.phillips@ku.edu.kw (O.A.P.); Husein.kamal@strath.ac.uk (H.J.K.) \\ 2 Strathclyde Institute of Pharmacy and Biomedical Sciences, University of Strathclyde, Glasgow G1 1XQ, UK \\ 3 Department of Pharmaceutical Analytical Chemistry, Faculty of Pharmacy, Ahram Canadian University, \\ Giza 12573, Egypt; hemmdan@yahoo.com \\ * Correspondence: dr.altannak@ku.edu.kw
}

check for updates

Citation: Al-Tannak, N.F.; Phillips,

O.A.; Kamal, H.J.; Hemdan, A.

Development and Validation of Stability-Indicating Assay Method for a Novel Oxazolidinone (PH-192) with Anticonvulsant Activity by Using UHPLC-QToF-MS. Molecules 2022, 27 , 1090. https://doi.org/10.3390/ molecules 27031090

Academic Editor: Alexis Oliva

Received: 30 December 2021

Accepted: 4 February 2022

Published: 6 February 2022

Publisher's Note: MDPI stays neutral with regard to jurisdictional claims in published maps and institutional affiliations.

Copyright: (C) 2022 by the authors. Licensee MDPI, Basel, Switzerland. This article is an open access article distributed under the terms and conditions of the Creative Commons Attribution (CC BY) license (https:// creativecommons.org/licenses/by/ $4.0 /)$.

\begin{abstract}
The treatment of seizure disorders with currently available pharmacotherapeutic agents is not optimal due to the failure of some patients to respond, coupled with occurrences of side effects. There is therefore a need for research into the development of new chemical entities as potential anticonvulsant agents, which are different structurally from the existing class of drugs. We recently identified a novel triazolyl-oxazolidinone derivative, $\mathrm{PH}-192$, as a potential anticonvulsant agent. $\mathrm{PH}-192$ demonstrated protection comparable to phenytoin against both chemically- and electricallyinduced seizures in rodents with little or no central nervous system side effects. However, PH-192 did not exhibit protection beyond $30 \mathrm{~min}$; therefore, we decide to investigate a stability-indicating assay of PH-192 in plasma and other solutions. A reliable and validated analytical method was developed to investigate the stability of PH-192 for 90 min in human plasma, acidic, basic, and oxidative conditions, using a Waters Acquity ultra high-performance liquid chromatography (UHPLC) system with a quaternary Solvent Manager (H-Class). A simple extraction method indicated that PH-192 was stable in human plasma after $90 \mathrm{~min}$ at $37^{\circ} \mathrm{C}$, with more than $90 \%$ successfully recovered. Moreover, stress stability studies were performed, and degradants were identified using LC-QToF-MS under acidic, basic, and oxidative simulated conditions.
\end{abstract}

Keywords: antimycobacterial activity; linezolid; PH-189; substituted-glycinyl triazolyl-oxazolidinone; GC-MS; UPLC

\section{Introduction}

Seizure disorders arise when brain nerve cells inappropriately and spontaneously fire action potentials, synchronously resulting in alterations in the sensory, motor, autonomic and psychological function of the afflicted individual. This manifestation of neuronal firing is called convulsion and the recurrent episodes of seizures result in a syndrome called epilepsy. Recurrent seizures significantly affect the quality of life and can sometimes be fatal if not adequately managed. Several anticonvulsant agents with different pharmacophores and chemical structures have been developed to control seizure disorders. However, effective, long-term control of this chronic condition with medication has not been very successful, with about $30 \%$ of the patients suffering from therapy-resistant epilepsy [1-4]. In addition, the use of most of these drugs is often accompanied by unwanted side effects. Therefore, there is considerable interest in the development of newer and more effective anticonvulsant agents that may cover several seizure types or treat currently untreatable seizures and with fewer side effects [5].

Oxazolidinone derivatives are exemplified by the presence of a five-membered heterocyclic ring system which has been identified as an important pharmacophoric group 
associated with the pharmacological properties of some clinically used drugs, namely, antibacterial, anticoagulant, and psychoactive agents [4,6-10]. Furthermore, systematic structural modification around the phenyl-oxazolidinone scaffold has yielded novel compounds with anticancer, antiepileptic, antithyroid, and more recently 5-lipoxygenase inhibitory properties $[9,11-15]$. The oxazolidinone-containing antibacterial agents, namely, linezolid 1 and tedizolid (2, Figure 1), have demonstrated clinical success with regards to their efficacy and safety profiles against susceptible and resistant Gram-positive cocci [16-19]. Based on these pharmacological properties, we previously reported the effects of a series of oxazolidinone derivatives on neuronal responses, which may correspond to their potential use as anticonvulsant agents with new pharmacophores [13-15]. Further structural modifications and in-vivo screening of selected derivatives' anticonvulsant activity in rodents, using both electrically and chemically induced models of seizures, showed that some of the compounds protected rats and mice in all models without any observable anticonvulsant side effects. The most efficacious and safest of these compounds, PH-192, protected the animals only for $30 \mathrm{~min}$ and not beyond [15]. PH-192 [20], a thiophene glycinyl-oxazolidinone-containing derivative (Figure 1) produced a dose-dependent protection from seizures induced by using a $6 \mathrm{~Hz}$ stimulation protocol with an estimated ED50 of $34.5 \mathrm{mg} / \mathrm{kg}$ and $90 \mathrm{mg} / \mathrm{kg}$ in mice and rats, respectively. Furthermore, pretreatment of mice and rats for $30 \mathrm{~min}$ with $100 \mathrm{mg} / \mathrm{kg}$ of $\mathrm{PH}-192$ for $30 \mathrm{~min}$ protected $75 \%$ and $66.6 \%$ of the animals, respectively, against $6 \mathrm{~Hz}$-induced seizures. In addition, a $30 \mathrm{~min}$ IP pretreatment of rats with $100 \mathrm{mg} / \mathrm{kg}$ PH- 192 protected $80 \%$ of the animals from seizure induced by pentylenetetrazole (PTZ) injection; this level of protection is comparable to that obtained for $40 \mathrm{mg} / \mathrm{kg}$ phenytoin, a reference antiepileptic drug that is clinically used for treating seizure disorders [15]. However, despite the favorable efficacy and safety profile of PH-192, the short duration of action (30 min) raised an important pharmacokinetic issue with this compound. Hence, prior to investigating the detailed pharmacokinetic behavior and brain distribution of $\mathrm{PH}-192$, we decided to investigate an in vitro stability-indicating assay in plasma, acidic, and basic conditions. Our aim was to shed some light on the physicochemical stability properties of this compound.
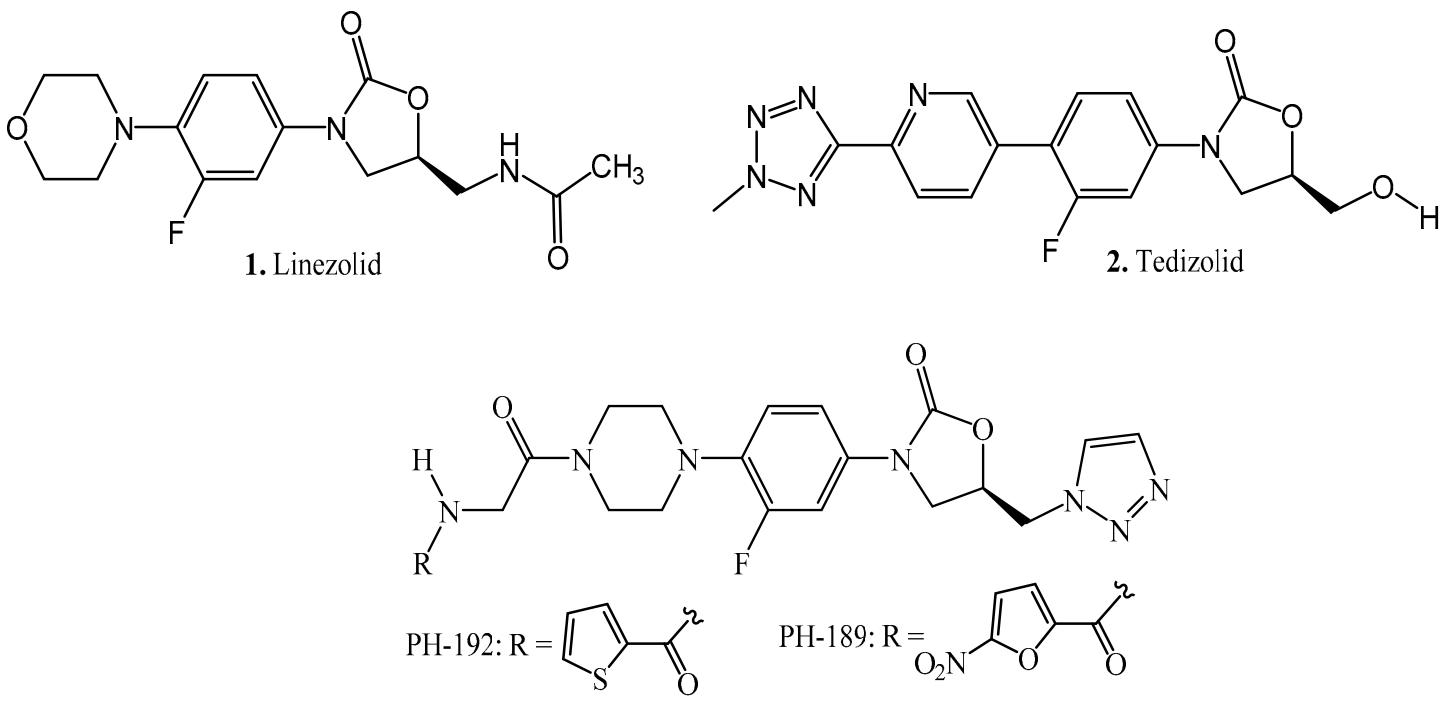

Figure 1. Chemical structures of oxazolidinones with antibacterial and anticonvulsant activities.

We hereby report the development of a fast, reliable, and validated bio-analytical liquid chromatography-mass spectrometric (LC-MS) method to investigate the plasma concentration of PH-192 in the presence of other biological constituents, as well as in acidic, basic, and oxidative conditions to indicate any products of instability. Different instrumental analytical methods have been reported in the scientific literature for assessing 
the analysis of structurally diverse oxazolidinone derivatives and their instability products in plasma [21-25].

\section{Results and Discussion}

As shown in Figure 2, the optimum resolution and peak shape were obtained with $0.1 \% v / v$ formic acid in water with acetonitrile $(75: 25 v / v)$ as a mobile phase. The flow rate was adjusted to $0.2 \mathrm{~mL} / \mathrm{min}$ for better resolution and rapid separation.

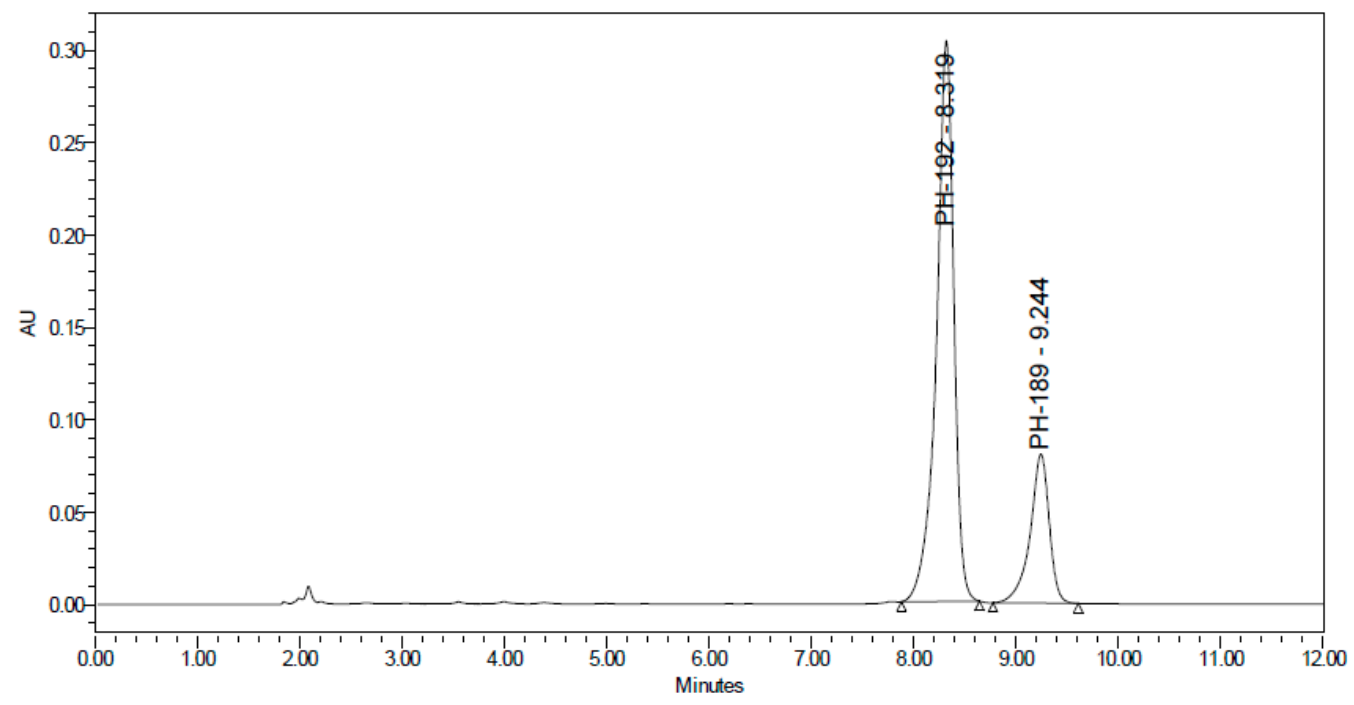

Figure 2. UHPLC-UV chromatogram of $40 \mu \mathrm{g} / \mathrm{mL}$ of PH-192 and $20 \mu \mathrm{g} / \mathrm{mL}$ of PH-189 as an internal standard.

\subsection{Method Validation}

\subsubsection{Linearity and Sensitivity}

Linearity was achieved by plotting peak areas (y) versus the concentrations in the range of $1-80 \mu \mathrm{g} / \mathrm{mL}$ for PH-192 with correlation coefficients $(\mathrm{r}) \geq 0.999$. As for the calibration curve, performed in triplicate, the slopes and correlation coefficients showed high consistency, which demonstrated the reliability of the standard curve over the concentration ranges studied, as shown in Table 1 . The LOQ was found to be $1 \mu \mathrm{g} / \mathrm{mL}$ for PH-192 with an RSD \% of $5.8 \%$. However, the LOD for PH-192 was found to be $0.33 \mu \mathrm{g} / \mathrm{mL}$, using $10 \mu \mathrm{L}$ as an injection volume, as shown in Table 1.

Table 1. Validation parameters of the proposed method.

\begin{tabular}{cc}
\hline Parameters & PH-192 \\
\hline Range $\mu \mathrm{g} / \mathrm{mL}$ & $1-80$ \\
Regression Equation & $y=0.0867 \mathrm{x}-0.0403$ \\
Correlation coefficient $(\mathrm{r})$ & 0.9998 \\
LOQ $(\mu \mathrm{g} / \mathrm{mL})$ & 1 \\
LOD $(\mu \mathrm{g} / \mathrm{mL})$ & 0.33 \\
Intra-assay precision $^{\mathrm{b}}$ & 5.8 \\
Inter-assay precision $^{\mathrm{b}}$ & 7.4 \\
Accuracy $^{\mathrm{c}}$ & $96.66 \%$ \\
\hline
\end{tabular}

b expressed as the RSD. ${ }^{\mathrm{c}}$ expressed as [mean \% deviation = mean calculated concentra-tion/nominal concentration].

\subsubsection{Precision and Accuracy}

In term of accuracy, the results were expressed as accuracy (\%) of PH-192 in the samples. The overall results of PH-192 are demonstrated in Table 2, indicating the accuracy of the proposed UHPLC-UV method. With respect to precision, the values of the \%RSD for 
intra-day and inter-day variations are given in Table 2 . The $\%$ RSD values in both cases were found to be acceptable within a $2 \%$ limit, indicating that the developed method is repeatable.

Table 2. Intra and inter- assay precision and accuracy data for PH-192 determination in bulk powder using UPLC-UV.

\begin{tabular}{ccccc}
\hline Precision & $\begin{array}{c}\text { PH-192 } \\
\text { Concentration } \\
\mu \mathrm{g} / \mathbf{m L}\end{array}$ & $\begin{array}{c}\text { Mean } \pm \text { SD } \\
(\boldsymbol{n}=\mathbf{3}) \\
\text { Observed/ } \boldsymbol{\mu g} / \mathbf{m L}\end{array}$ & $\begin{array}{c}\text { Precision } \\
\mathbf{a}(\mathbf{\%})\end{array}$ & $\begin{array}{c}\text { Accuracy } \\
\mathbf{b}(\%)\end{array}$ \\
\hline Intra-Assay Precision And Accuracy & 1 & $0.966 \pm 0.056$ & 5.8 & 96.66 \\
Data for PH-192 Determination in & 20 & $19.91 \pm 0.158$ & 0.8 & 99.55 \\
Bulk Powder Using UPLC-UV. & 80 & $79.96 \pm 0.165$ & 0.2 & 99.96 \\
\hline Inter-Assay Precision And Accuracy & 1 & $0.943 \pm 0.070$ & 7.4 & 94.33 \\
Data for PH-192 Determination in & 20 & $19.77 \pm 0.305$ & 1.5 & 98.85 \\
Bulk Powder Using UPLC-UV. & 80 & $79.27 \pm 0.409$ & 0.5 & 99.08 \\
\hline
\end{tabular}

a expressed as the RSD. ${ }^{b}$ expressed as [mean \% deviation = mean calculated concentration/nominal concentration $\times 100]$.

\subsubsection{Evaluation of PH-192 Extraction and Stability in Human Plasma}

The efficiency of the extraction method of $\mathrm{PH}-192$ using liquid-liquid extraction was assessed by calculating the extraction recovery percentages. The extraction recovery was estimated from the peak areas of $\mathrm{PH}-192$ in plasma and mobile phase. The extraction method was capable of extracting $94.38 \%$ of $\mathrm{PH}-192$ from human plasma. PH-192 showed good stability in human plasma for $90 \mathrm{~min}$ at a temperature of $37^{\circ} \mathrm{C}$ and no degradants were detected. The amount of $\mathrm{PH}-192$ was calculated from the calibration curve equation and was found to be equivalent to $9.44 \mu \mathrm{g} / \mathrm{mL}$ out of $10 \mu \mathrm{g} / \mathrm{mL}$ of PH-192, which was spiked in the human plasma.

\subsubsection{Stability Study}

PH-192 with a molecular weight of $513.5 \mathrm{~g} / \mathrm{mol}$ was subjected to basic degradation by $1 \mathrm{~N} \mathrm{NaOH}$ and heating at $90{ }^{\circ} \mathrm{C}$ for $90 \mathrm{~min}$. There was one main degradation product detected via UHPLC-UV and was eluted around $5.9 \mathrm{~min}$, as shown in Figure 3. The degradation product was identified and confirmed by LC-QToF-MS, as shown in Figures 3-5. Moreover, $\mathrm{PH}-192$ was exposed to oxidation by $1 \mathrm{~N} \mathrm{H}_{2} \mathrm{O}_{2}$ and a main degradant product was detected by UHPLC-UV at $1.8 \mathrm{~min}$ as shown in Figure 6. LC-QToF was used to identify the degradation products, as shown in Figures 7 and 8 [25]. On the other hand, PH-192 was found to be stable when subjected to $1 \mathrm{~N} \mathrm{HCl}$.

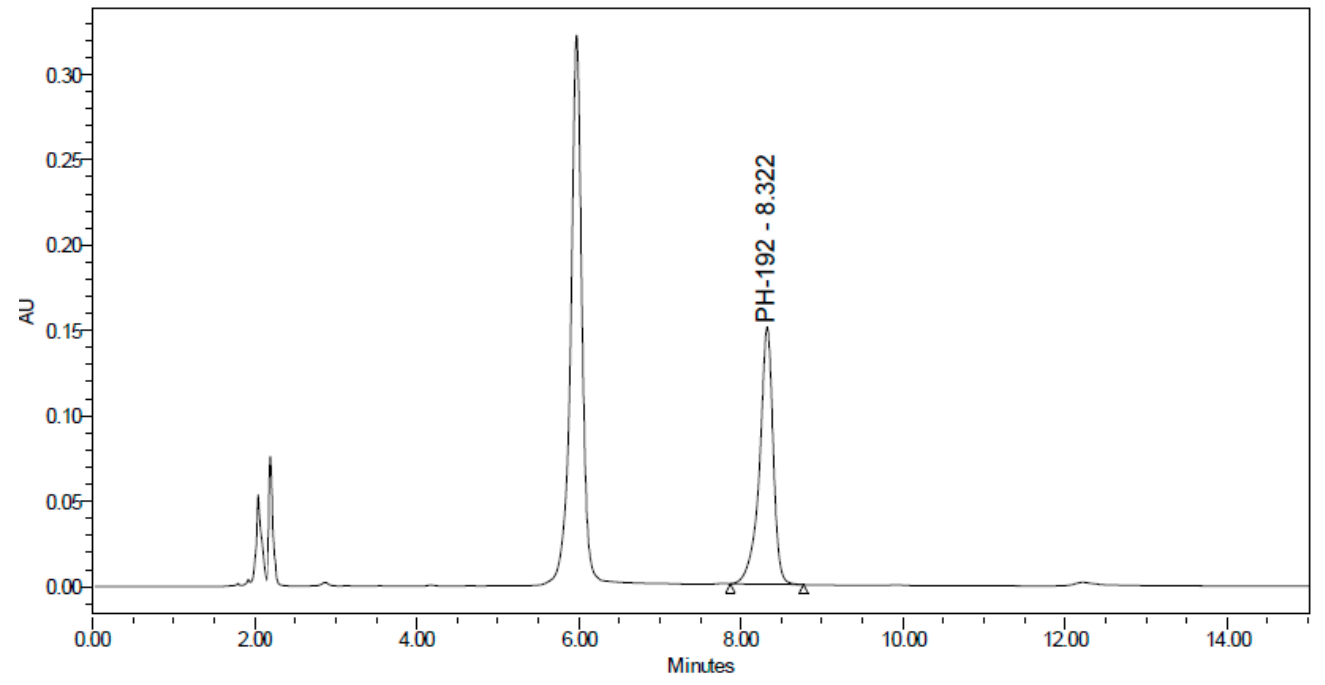

Figure 3. UHPLC-UV chromatogram for the basic degradation products of PH-192. 


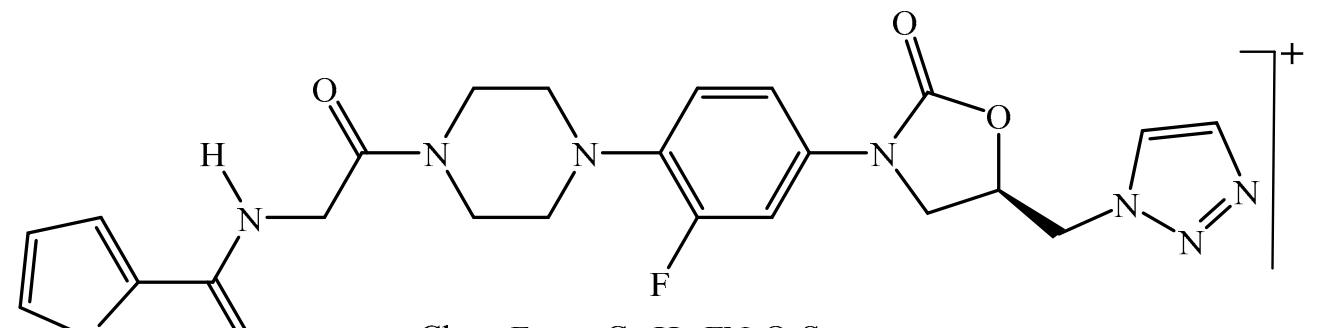

Chem Form: $\mathrm{C}_{23} \mathrm{H}_{24} \mathrm{FN}_{7} \mathrm{O}_{4} \mathrm{~S}$

Exact Mass: 513.16

Mol Wt: 513.55

$[M+H=514.1668]$

$1 \mathrm{M} \mathrm{NaOH} \downarrow$

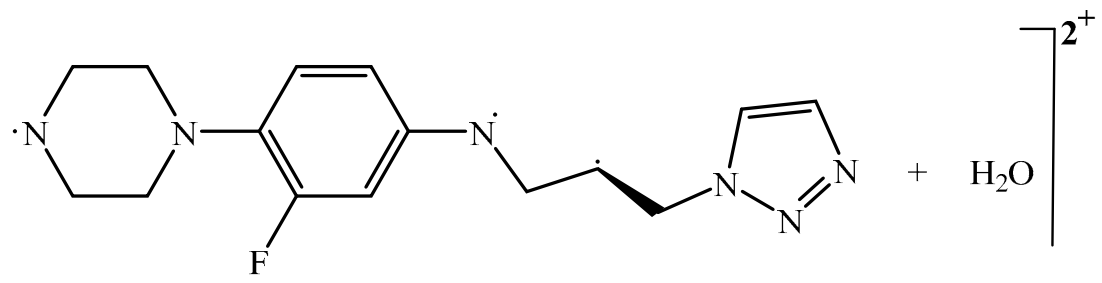

Chemical Formula: $\mathrm{C}_{15} \mathrm{H}_{18} \mathrm{FN}_{6}{ }^{3 \cdot}$

Exact Mass: 301.16

$[\mathrm{M}+\mathbf{2 H}+\mathbf{H 2 O}=\mathbf{3 2 1 . 1 6}]$

Figure 4. Degradation product of $\mathrm{PH}-192$ after adding $1 \mathrm{~N}$ of $\mathrm{NaOH}$.

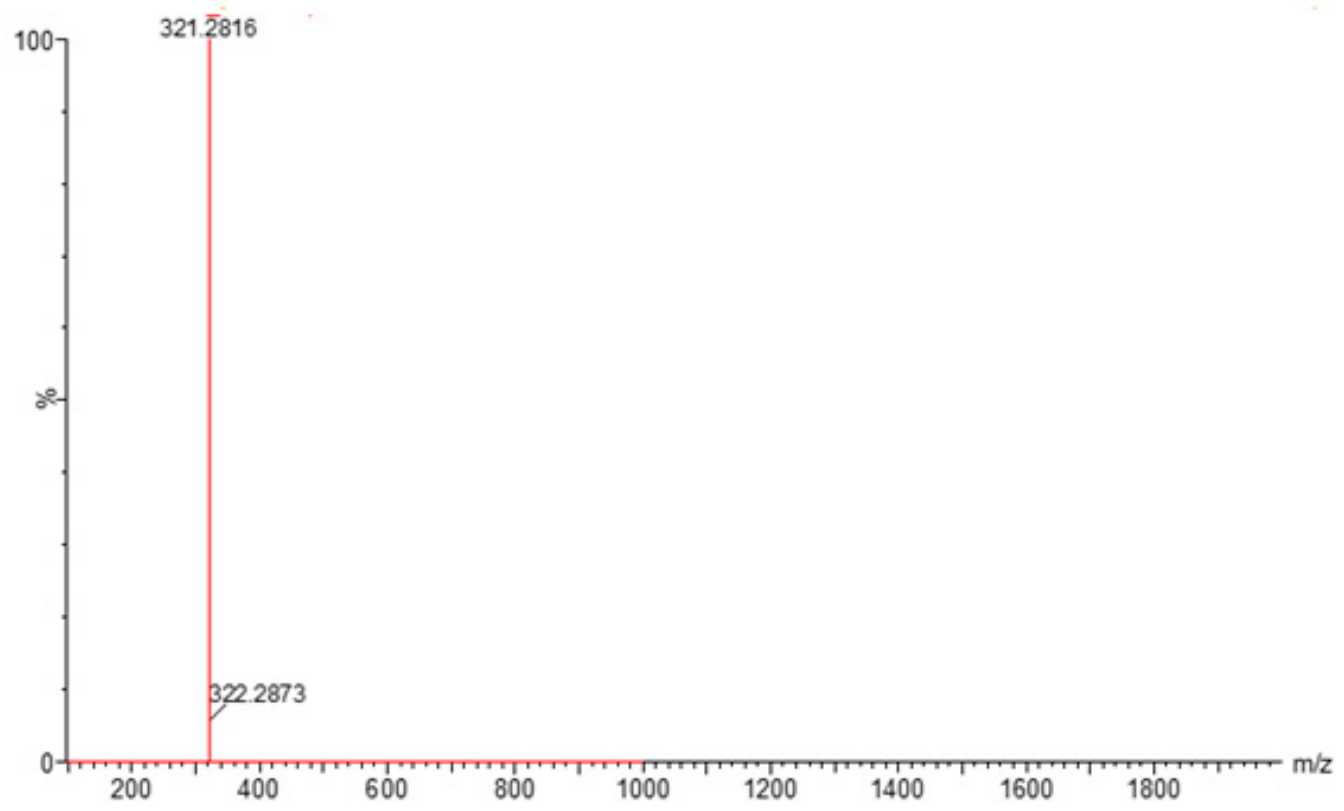

Figure 5. LC-QToF-MS analysis of $\mathrm{PH}-192$ post-exposure to basic degradation. 


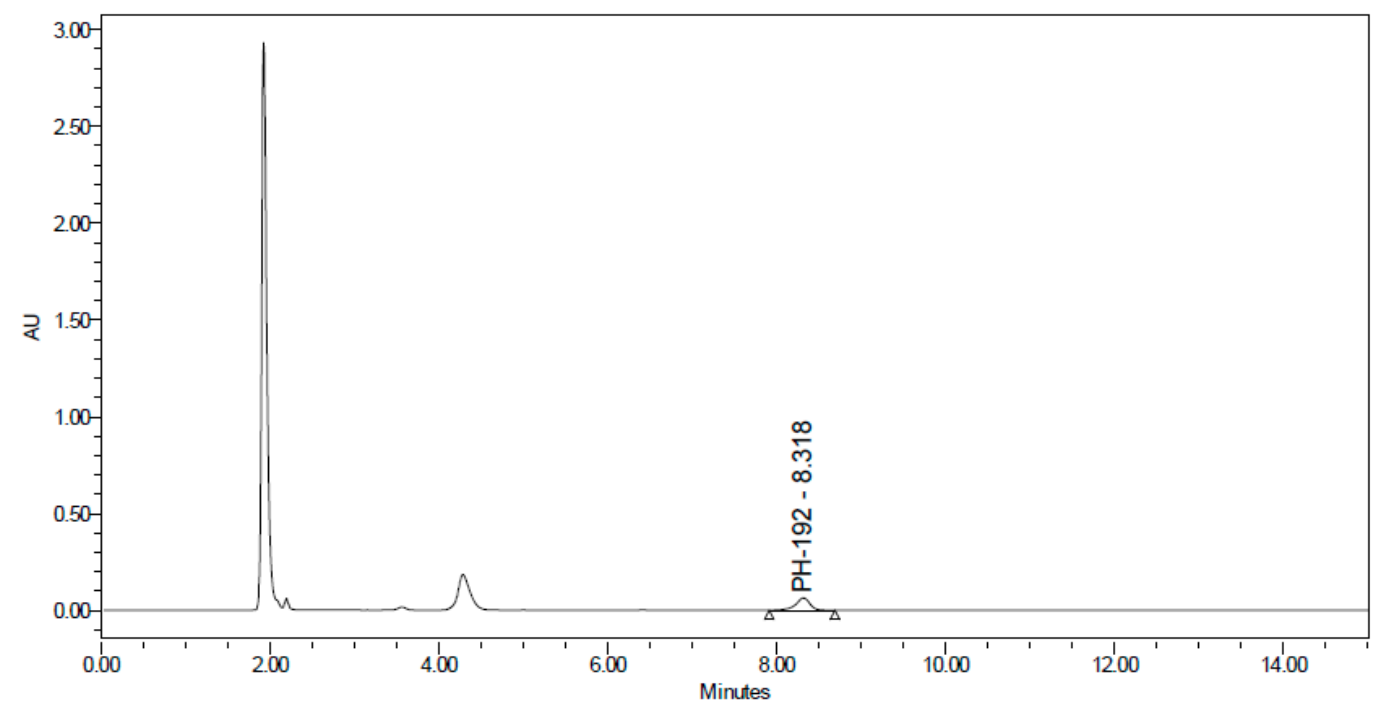

Figure 6. UHPLC-UV chromatogram for the oxidation degradation products of PH-192.

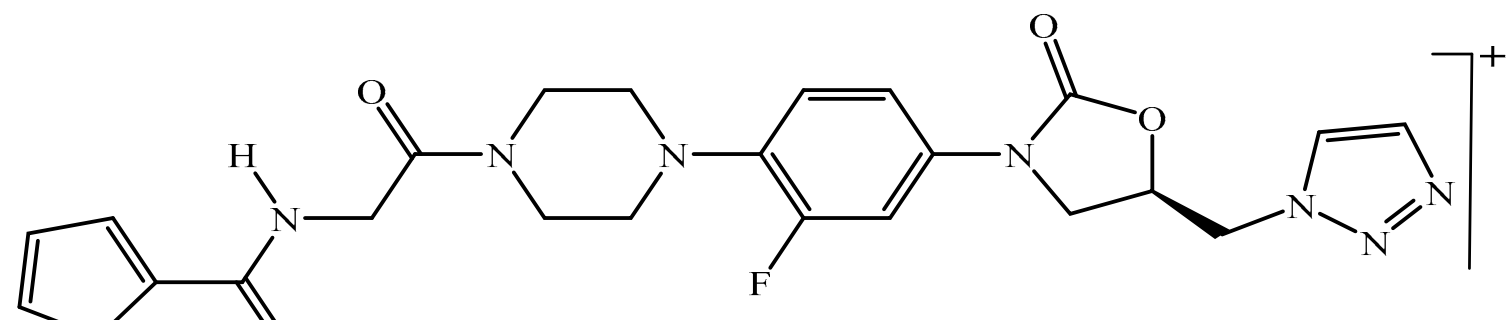

Chem Form: $\mathrm{C}_{23} \mathrm{H}_{24} \mathrm{FN}_{7} \mathrm{O}_{4} \mathrm{~S}$

Exact Mass: 513.16

Mol Wt: 513.55

$[\mathrm{M}+\mathrm{H}=\mathbf{5 1 4 . 1 6 6 8 ]}$
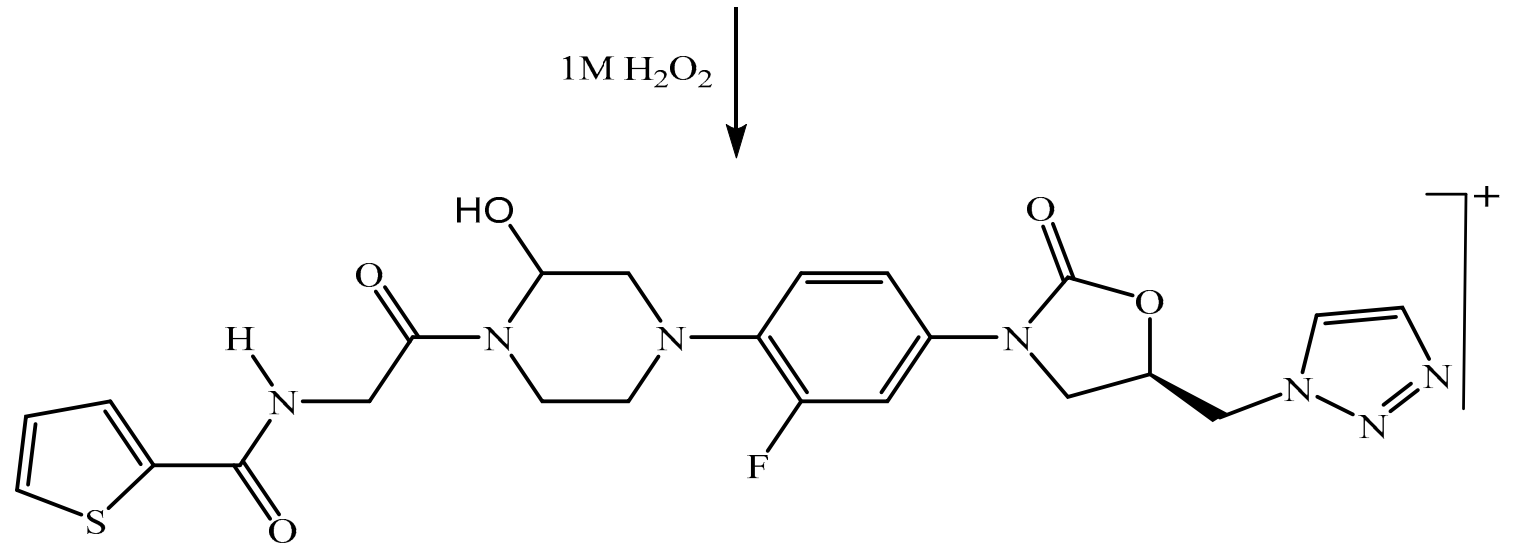

Chem Form: $\mathrm{C}_{23} \mathrm{H}_{24} \mathrm{FN}_{7} \mathrm{O}_{5} \mathrm{~S}$

Exact Mass: 529.15

Mol Wt: 529.55

$[\mathrm{M}+\mathrm{H}=\mathbf{5 3 0 . 1 6 6 3 ]}$

Figure 7. Degradation products of $\mathrm{PH}-192$ after adding $1 \mathrm{~N}$ of $\mathrm{H}_{2} \mathrm{O}_{2}$. 


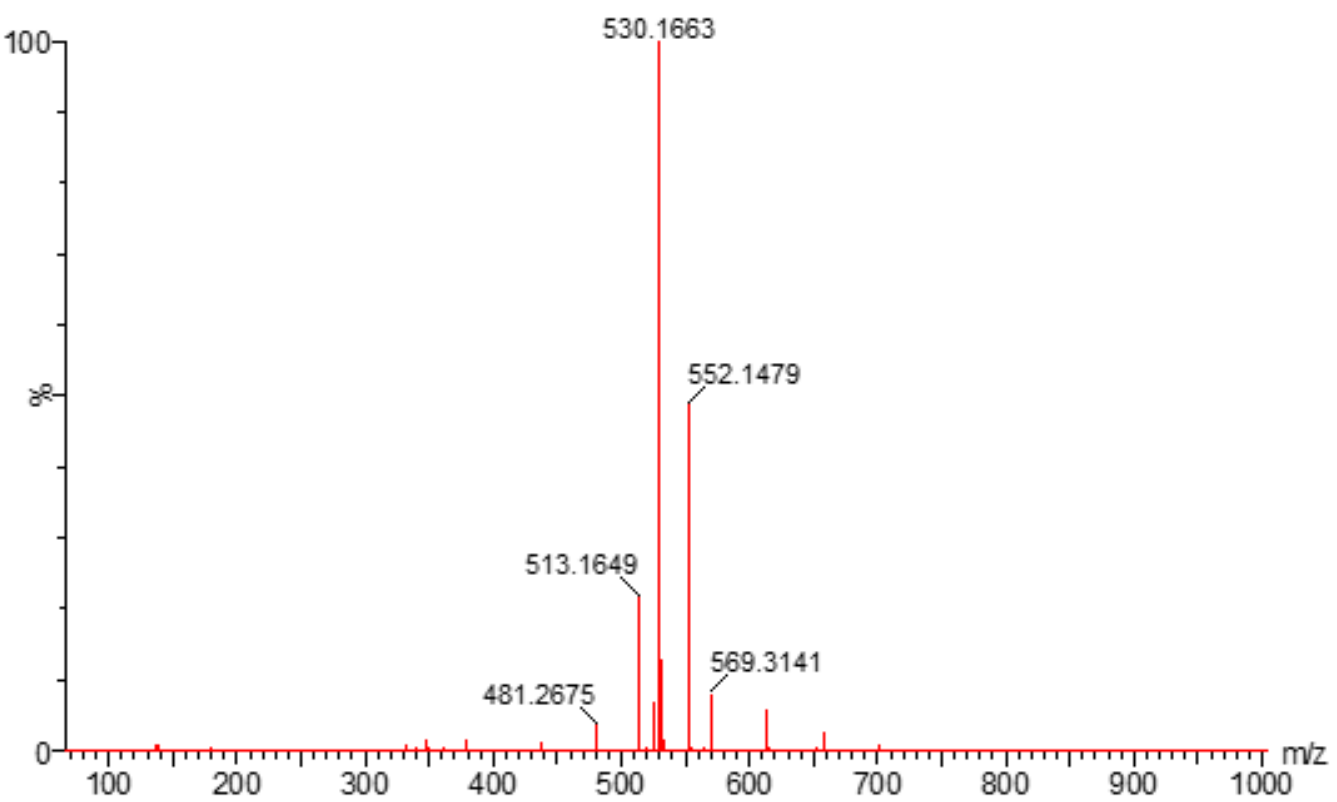

Figure 8. LC-QToF-MS analysis of PH-192 post-exposure to oxidation degradation.

\section{Materials and Methods}

\subsection{Chemicals}

Drug-free human plasma was obtained from Kuwait Blood Bank, Al Jabriyah, Kuwait. HPLC-grade acetonitrile and other chemicals used in the adopted method were of analytical grade and obtained from Sigma Aldrich, Dorset, UK. "In-house" HPLC grade water was prepared with a MilliQ filter purchased from Millipore, Watford, UK. Syringe membrane filters $(13 \mathrm{~mm})$ were purchased from kinesis scientific expert, Cambridgeshire, UK. Nylon solvent filters (0.45 um) were used for solvent filtration and Water 20-positions.

\subsection{Solutions}

Stock standard solutions of $\mathrm{PH}-192$ and the internal standard (PH-189) were prepared separately by dissolving $10 \mathrm{mg}$ of the compounds in $10 \mathrm{~mL}$ of water:acetonitrile $(75: 25 \mathrm{v} / \mathrm{v})$ to give stock concentrations of $1 \mathrm{mg} / \mathrm{mL}$. Working solutions of PH-192 and the internal standard were prepared by diluting the stock solutions with water:acetonitrile $(75: 25 v / v)$ to obtain concentration of $500 \mu \mathrm{g} / \mathrm{mL}$. Stock solutions were stable for at least 5 weeks when stored in a refrigerator $\left(4^{\circ} \mathrm{C}\right)$.

\subsection{Human Plasma Extraction Procedure}

Aliquots of $200 \mu \mathrm{L}$ of human plasma were mixed with $10 \mu \mathrm{g} / \mathrm{mL}$ of PH-192. PH-192 was extracted by transferring $210 \mu \mathrm{L}$ of human plasma to an Eppendorf tube, followed by the addition of $770 \mu \mathrm{L}$ of acetonitrile (ACN) containing $20 \mu \mathrm{L}$ of PH-189 as an internal standard and then vortexed. The samples were then centrifuged at 8000 revolutions per minute for $10 \mathrm{~min}$. The supernatant was then collected into an HPLC vial as a final solution, ready for LC-MS analysis.

\subsection{Instrumentation}

\subsubsection{Ultra-Pressure Liquid Chromatography}

Isocratic elution was carried out on a Waters Acquity UHPLC system with a quaternary Solvent Manager (H-Class), Sample Manager, and a UV detector, ACE C18 $(50 \times 3.0 \mathrm{~mm}$, $3 \mu \mathrm{m})$ analytical columns were used for the analysis and method validation. Empower ${ }^{\circledR}$ software was used for data processing and reporting. The mobile phase comprised filtered and degassed $0.1 \%$ formic acid in water and acetonitrile in proportion of 75:25 $v / v$ and pumped at a flow rate of $0.2 \mathrm{~mL} / \mathrm{min}$. Column temperature was set to $30^{\circ} \mathrm{C}$ and $10 \mu \mathrm{L}$ of the sample was injected and analyzed at a wavelength of $254 \mathrm{~nm}$. 


\subsubsection{Liquid Chromatography-Mass Spectrometry}

Waters ${ }^{\circledR}$ Xevo G2-S QToF coupled with Waters ${ }^{\circledR}$ Acquity UPLC system with binary Solvent Manager (I-Class) via the ESI interface. The operating parameters in the positive ion mode were as follows: the sheath gas and auxiliary flow rates were set at 30 and 5 (arbitrary units), respectively. The capillary voltage was set at $3.5 \mathrm{~V}$, sampling cone was $55 \mathrm{~V}$, and source temperature was $110^{\circ} \mathrm{C}$. Source temperature and desolvation temperature were set at $110^{\circ} \mathrm{C}$ and $450{ }^{\circ} \mathrm{C}$, respectively. Collision energy-2: $10 \mathrm{eV}, 3: 15 \mathrm{eV}, 4: 20 \mathrm{eV}$.

\subsubsection{Calibration Procedure for Mass Spectrometry}

The calibration of mass spectrometry was achieved using an internal calibration procedure. Leucine enkephalin $(m / z=556.2771)$ was used as a reference compound and introduced to the ionization source at the same time as PH-192. As shown in Supplementary Materials Figure S1, the error was less than $1 \mathrm{ppm}$ as the detected $m / z$ for leucine encephalin was 556.2772 . Sodium formate solution ( $0.5 \mu \mathrm{M}$ solution) was used as a standard to calibrate the analyzer and MS/MS calibration to assess the accuracy and resolution, as shown in Figures S2 and S3.

\subsection{Method Validation}

Validation of the method was performed according to The International Council for Harmonisation $(\mathrm{ICH})$ guidelines.

\subsubsection{Calibration Curve}

Accurately measured aliquots of $\mathrm{PH}-192$ were transferred from the working standard solution $(1 \mathrm{mg} / \mathrm{mL})$ into a series of $10 \mathrm{~mL}$ volumetric flasks and filled to volume with the mobile phase. The calibration samples consisted of five concentrations of PH-192 (1-80 $\mu \mathrm{g} / \mathrm{mL})$. The samples were injected separately into the ACE C18 column under a flow rate of $0.2 \mathrm{~mL} / \mathrm{min}$. The peak area of each drug was recorded against its concentration, the linearity of the curves was constructed, and regression equations were computed.

\subsubsection{Accuracy and Precision}

The accuracy of the results was determined by calculating the accuracy (\%) of three replicates of three different concentrations covering the linearity. The concentrations were calculated from the corresponding regression equations. The precision of the UHPLCUV method for the combination was assessed by preparing six sets of PH-192 in the concentration ranges of the calibration curve. The precision of the UHPLC-UV method for PH-192 was estimated by preparing three different concentrations of pure standards of PH-192 $(1,20$, and $80 \mu \mathrm{g} / \mathrm{mL})$ within the linear range; samples were analyzed in triplicate, on a single day and three consecutive days, to calculate the intra-day repeatability and inter-day precision (intermediate precision) of the proposed method, respectively. A set $(n=3)$ was prepared at room temperature $\left(22^{\circ} \mathrm{C}\right)$, whereas five other sets $(n=3)$ were prepared and stored at $4{ }^{\circ} \mathrm{C}$ for mixtures dissolved in mobile phase samples for three days. The relative standard deviation percentage (\%RSD) was used to calculate the intra- and inter-assay precision.

\subsubsection{Extraction Recovery and Matrix Effect}

Two sets of standards containing 1, 20, 40, and $80 \mu \mathrm{g} / \mathrm{mL}$ of PH-192 were prepared. One set was prepared in human plasma and the other set in the mobile phase. The plasma standards were mixed with $20 \mu \mathrm{g} / \mathrm{mL}$ of internal standard and extracted as mentioned previously, whereas the standards of the other set were directly injected after mixing with internal standard (non-extracted samples). The extraction recoveries were calculated based on the slopes of the standard curve of PH-192 in the plasma and the mobile phase. Absolute recoveries of PH-192 and internal standard were also indicated by comparing the absolute values of the peak areas of PH-192 and internal standard in extracted and non-extracted samples. 


\subsubsection{Evaluation of PH-192 Extraction and Stability in Human Plasma}

A sample containing $20 \mu \mathrm{g} / \mathrm{mL}$ of PH-192 and $20 \mu \mathrm{g} / \mathrm{mL}$ of the internal standard were spiked in human plasma and placed in an oven for $90 \mathrm{~min}$ at $37^{\circ} \mathrm{C}$. PH- 192 and the internal standard were extracted from plasma using liquid-liquid extraction and filtered by means of syringe membrane filters $(13 \mathrm{~mm})$ kinesis $^{\circledR}$.

\subsubsection{Limit of Detection (LOD) and Limit of Quantification (LOQ)}

Stock solutions of PH-192 were prepared at concentrations of 1-100 $\mu \mathrm{g} / \mathrm{mL}$. The LOD and LOQ for PH-192 was determined at signal-to-noise ratios of 3:1 and 10:1, respectively.

\subsection{Forced Degradation Studies}

All stability tests were done on the active pharmaceutical ingredients and pharmaceutical formulations to simulate the actual conditions to which the dosage forms would be exposed during storage.

\subsubsection{Acidic Degradation}

PH-192 (2 mg) was weighed and placed in a $4 \mathrm{~mL}$ vial. Two milliliters of $1 \mathrm{~N} \mathrm{HCl}$ were added and heated at $90{ }^{\circ} \mathrm{C}$ for $90 \mathrm{~min}$, allowed to cool down for $15 \mathrm{~min}$, and then analyzed by means of LC-MS.

\subsubsection{Basic Degradation}

PH-192 (2 mg) was placed in a $4 \mathrm{~mL}$ vial and subjected to basic stress conditions by adding $2 \mathrm{~mL}$ of $1 \mathrm{~N} \mathrm{NaOH}$. The sample was heated at $90{ }^{\circ} \mathrm{C}$ for $90 \mathrm{~min}$, allowed to cool down for $15 \mathrm{~min}$, and then analyzed by means of LC-MS.

\subsubsection{Oxidation Degradation}

PH-192 (2 mg) was placed in a $4 \mathrm{~mL}$ vial and subjected to oxidative conditions by adding $2 \mathrm{~mL}$ of $1 \mathrm{~N} \mathrm{H}_{2} \mathrm{O}_{2}$. The sample was then heated at $90{ }^{\circ} \mathrm{C}$ for $90 \mathrm{~min}$, allowed to cool down for $15 \mathrm{~min}$, and then analyzed by means of LC-MS.

\section{Conclusions}

Previous studies from our laboratory demonstrated that PH-192 $(100 \mathrm{mg} / \mathrm{kg})$ exhibited a time-dependent protection of rodents exposed to both chemically and electrically induced seizures with a peak effect at $30 \mathrm{~min}$ post-treatment and no observable protection at $2 \mathrm{~h}$ post-treatment. Thus, a fast, accurate, and reliable LC-ESI-QToF analytical method was established for the quantitation and stability indications of the novel oxazolidinone PH-192. This compound was found to be stable in acidic stress conditions after using $1 \mathrm{~N} \mathrm{HCl}$; however, in basic $1 \mathrm{~N} \mathrm{NaOH}$ and oxidative $1 \mathrm{~N}$ hydrogen peroxide solutions it was found to be unstable. Moreover, compound $\mathrm{PH}-192$ was found to be stable in human plasma for $90 \mathrm{~min}$ at $37^{\circ} \mathrm{C}$ with a high percentage of recovery; therefore, it is a potent candidate that can be subjected to pharmacological studies in-vivo in animal anticonvulsant models.

Supplementary Materials: The following supporting information can be downloaded online. Figure S1: Spectrum for Leucine enkephalin as internal standard for mass spectrometry calibration; Figure S2: Mass Spectrometry accuracy assessment achieved using $0.5 \mu \mathrm{M}$ sodium formate, Figure S3: Mass Spectrometry resolution assessment achieved using $0.5 \mu \mathrm{M}$ sodium formate.

Author Contributions: Conceptualization, O.A.P. and N.F.A.-T.; the synthesis of PH-192 was performed in the laboratory of O.A.P.; methodology, O.A.P. and N.F.A.-T.; UHPLC analysis and stability indicating studies were performed in the laboratory of N.F.A.-T.; software validation, O.A.P., N.F.A.-T., H.J.K. and A.H.; investigations, O.A.P. and N.F.A.-T.; writing-review and editing, O.A.P., H.J.K., A.H. and N.F.A.-T.; visualization, O.A.P., N.F.A.-T. and H.J.K.; supervision project, O.A.P. and N.F.A.-T. All authors have read and agreed to the published version of the manuscript.

Funding: This research received no external funding. 
Institutional Review Board Statement: Not applicable.

Informed Consent Statement: Not applicable.

Data Availability Statement: Not applicable.

Acknowledgments: The Department of Pharmaceutical Chemistry, Faculty of Pharmacy, Kuwait University provided the facilities and instruments used to accomplish this study.

Conflicts of Interest: The authors declare no conflict of interest.

Sample Availability: Samples of the compounds are not available from the authors.

\section{References}

1. Brodie, M.J. Do we need any more new antiepileptic drugs? Epilepsy Res. 2001, 45, 3-6. [CrossRef]

2. Löscher, W. Current status and future directions in the pharmacotherapy of epilepsy. Trends Pharmacol. Sci. 2002, 23, 113-118. [CrossRef]

3. Löscher, W.; Klitgaard, H.; Twyman, R.E.; Schmidt, D. New avenues for anti-epileptic drug discovery and development. Nat. Rev. Drug Discov. 2013, 12, 757-776. [CrossRef]

4. $\quad$ Pitkänen, A.; Ndode-Ekane, X.E.; Lukasiuk, K.; Wilczynski, G.M.; Dityatev, A.; Walker, M.C.; Chabrol, E.; Dedeurwaerdere, S.; Vazquez, N.; Powell, E.M. Neural ECM and epilepsy. Prog. Brain Res. 2014, 214, 229-262.

5. Hen, N.; Bialer, M.; Yagen, B. Syntheses and evaluation of anticonvulsant activity of novel branched alkyl carbamates. J. Med. Chem. 2014, 55, 2835-2845. [CrossRef] [PubMed]

6. $\quad$ Reck, F.; Zhou, F.; Girardot, M.; Kern, G.; Eyermann, C.J.; Hales, N.J.; Ramsay, R.R.; Gravestock, M.B. Identification of 4-substituted 1,2,3-triazoles as novel oxazolidinone antibacterial agents with reduced activity against monoamine oxidase A. J. Med. Chem. 2005, 48, 499-506. [CrossRef] [PubMed]

7. Bolasco, A.; Carradori, S.; Fioravanti, R. Focusing on new monoamine oxidase inhibitors. Expert Opin. Ther. Pat. 2010, 20, 909-939. [CrossRef] [PubMed]

8. Leach, K.L.; Brickner, S.J.; Noe, M.C.; Miller, P.F. Linezolid, the first oxazolidinone antibacterial agent. Ann. N. Y. Acad. Sci. 2011, 1222, 49-54. [CrossRef]

9. Pandit, N.; Singla, R.K.; Shrivastava, B. Current updates on oxazolidinone and its significance. Int. J. Med. Chem. 2012, 2012, 159285. [CrossRef]

10. Phillips, O.A.; Sharaf, L.H. Oxazolidinone antimicrobials: A patent review (2012-2015). Expert Opin. Ther. Pat. 2016, 26, 591-605. [CrossRef]

11. Hedaya, O.M.; Mathew, P.M.; Mohamed, F.H.; Phillips, O.A.; Luqmani, Y.A. Antiproliferative activity of a series of 5(1H1,2,3triazolyl) methyl and 5acetamidomethyloxazolidinone derivatives. Mol. Med. Rep. 2016, 13, 3311-3318. [CrossRef] [PubMed]

12. Al-Hasawi, N.A.; Phillips, O.A.; Al-Awadhi, F.; Sharaf, L.H.; Amine, S.A.; Novotny, L. Anti-progressive effects of a series of glycinyl and alaninyl triazolyl-oxazolidinones on Kelly neuroblastoma cell line. Anticancer Res. 2020, 40, 5125-5140. [CrossRef]

13. Kombian, S.B.; Phillips, O.A. In vitro electrophysiological investigations of the acute effects of linezolid and novel oxazolidinones on central nervous system neurons. Neuroscience 2011, 180, 53-63. [CrossRef]

14. Qaddoumi, M.G.; Phillips, O.A.; Kombian, S.B. A novel oxazolidinone derivative PH192 demonstrates anticonvulsant activity in-vivo in rats and mice. Eur. J. Pharm. Sci. 2019, 130, 21-26. [CrossRef]

15. Phillips, O.A.; Bosso, M.A.; Ezeamuzie, C.I. Synthesis and structure-activity relationships of novel 5-(hydroxamic acid)methyl oxazolidinone derivatives as 5-lipoxygenase inhibitors. J. Enzym. Inhib. Med. Chem. 2020, 35, 1471-1482. [CrossRef]

16. Moran, G.J.; De Anda, C.; Das, A.F.; Green, S.; Mehra, P.; Prokocimer, P. Efficacy and Safety of Tedizolid and Linezolid for the Treatment of Acute Bacterial Skin and Skin Structure Infections in Injection Drug Users: Analysis of Two Clinical Trials. Infect. Dis. Ther. 2018, 7, 509-522. [CrossRef]

17. Bassetti, M.; Castaldo, N.; Carnelutti, A.; Peghin, M.; Giacobbe, D.R. Tedizolid phosphate for the treatment of acute bacterial skin and skin-structure infections: An evidence-based review of its place in therapy. Core Evid. 2019, 14, 31-40. [CrossRef] [PubMed]

18. Luque, S.; Hope, W.; Sorli, L.; Muñoz-Bermudez, R.; Campillo, N.; Barceló-Vidal, J.; Álvarez-Lerma, F.; Horcajada, J.P.; MasclansEnviz, J.R.; Neely, M.; et al. Dosage Individualization of Linezolid: Precision Dosing of Linezolid to Optimize Efficacy and Minimize Toxicity. Antimicrob. Agents Chemother. 2021, 65, e02490-20. [CrossRef] [PubMed]

19. Mensa Vendrell, M.; Tasias Pitarch, M.; Salavert Lletí, M.; Calabuig Muñoz, E.; Morata Ruiz, L.; Castells Lao, G.; López Suñé, E.; Mensa Pueyo, J.; Oltra Sempere, M.R.; Pedro-Botet Montoya, M.L.; et al. Safety and Tolerability of More than Six Days of Tedizolid Treatment. Antimicrob. Agents Chemother. 2020, 64, e00356-20. [CrossRef]

20. Phillips, O.A.; Udo, E.E.; Abdel-Hamid, M.E.; Varghese, R. Synthesis and antibacterial activities of N-substituted-glycinyl 1H-1,2,3-triazolyl oxazolidinones. Eur. J. Med. Chem. 2013, 66, 246-257. [CrossRef]

21. Bae, S.; Kim, E.J.; Kwon, J.W.; Kim, W.; Lee, M. High-performance liquid chromatographic analysis of DA-7867, a new oxazolidinone, in human plasma and urine and in rat tissue homogenates. J. Chromatogr. B Anal. Technol. Biomed. Life Sci. 2003, 794, 397-403. [CrossRef] 
22. Phillips, O.; Abdel-Hamid, M. Determination of Novel Antibacterial Triazolylmethyl Oxazolidinones Concentrations in Human Plasma by APCI-LCMS: Application to Stability Study. J. Pharm. Pharm. Sci. 2008, 11, 22s-31s. [CrossRef]

23. Phillips, O.; Sharaf, L.; Abdel-Hamid, M.; Varghese, R. Assessment of the Stability of Novel Antibacterial Triazolyl Oxazolidinones Using a Stability-Indicating High-Performance Liquid Chromatography Method. Med. Princ. Pract. 2011, 20, 51-59. [CrossRef] [PubMed]

24. Cavazos-Rocha, N.; Carmona-Alvarado, I.; Vera-Cabrera, L.; 'Waksman-de-Torres, N.; de la Luz Salazar-Cavazos, M. HPLC Method for the Simultaneous Analysis of Fluoroquinolones and Oxazolidinones in Plasma. J. Chromatogr. Sci. Adv. 2014, 52, 1281-1287. [CrossRef] [PubMed]

25. Al-Tannak, N.; Phillips, O. Antimycobacterial Activities of N-SubstitutedGlycinyl 1H1,2,3-Triazolyl Oxazolidinones and Analytical Method Development and Validation for a Representative Compound. Sci. Pharm. 2017, 85, 34. [CrossRef] 